\title{
PReS-FINAL-2053: Vitamin D receptor polymorphisms in a cohort of Italian patients with juvenile idiopathic arthritis
}

\author{
F Falcini ${ }^{* *}$, F Marini ${ }^{2}$, D Rigante ${ }^{3}$, F Bertini ${ }^{1}$, G Lepri ${ }^{1}$, S Stagi ${ }^{4}$, M Matucci Cerinic ${ }^{5}$, ML Brandi ${ }^{2}$ \\ From 20th Pediatric Rheumatology European Society (PReS) Congress \\ Ljubljana, Slovenia. 25-29 September 2013
}

\section{Introduction}

A role for vitamin D has been hypothesized in generating disease activity for patients with juvenile idiopathic arthritis (JIA): specific polymorphisms of vitamin D receptor $(V D R)$ gene have recently been associated with different biologic response to vitamin $\mathrm{D}$ itself.

\section{Objectives}

To evaluate $V D R$ polymorphisms in patients with JIA in comparison with unrelated healthy controls.

\section{Methods}

We recruited 63 Italian children, adolescents and young adults with JIA (mean age 16.21 + 7.11 SD yrs, 51 female and 12 males, female/male ratio 4.25 from 1 Unit of Paediatric Rheumatology and 1 Unit of Rheumatology, Transition Clinic. After informed consent, during routine laboratory tests, their genomic DNA was extracted from peripheral blood leukocytes, to analyze $V D R$ polymorphisms by PCR-based sequencing (CDX2 in the promoter region) and PCR-based enzymatic digestions (FokI in exon 2, BsmI and ApaI in intron 8, and TaqI in exon 9). An Italian population of 2221 unrelated individuals without JIA was used as healthy controls.

\section{Results}

The distribution of FokI, BsmI, ApaI, and TaqI polymorphisms did not show significant differences between children with JIA and controls. Regarding the CDX2 polymorphism, we observed a statistical difference in the distribution of GG and GA genotypes, with the GG genotype more frequent in JIA subjects (Yates-corrected chi-square

${ }^{1}$ Internal Medicine, Rheumatology Section, Transition Clinic, Italy Full list of author information is available at the end of the article
6.97; Odds ratio $=2.08 ; p=0.008)$ and the GA genotype in healthy controls (Yates-corrected chi-square 4.04; Odds ratio $=0.55 ; p=0.044)$. Data about AA genotype were not significant due to their very low number (three) within the JIA population. $G$ allele resulted to be more frequent in JIA subjects (Yates-corrected chi-square 6.51; Odds ratio $=1.82 ; p=0.011$.

\section{Conclusion}

Pathogenetic mechanisms influencing the predisposition to JIA are poorly elucidated. Our analysis of $C D X 2$ polymorphisms located in the promoter region of the $V D R$ gene has revealed that both GG genotype and G allele are more represented in patients with JIA. By our preliminary data, we can speculate that the G allele decreases VDR transcriptional activity with respect to the A allele, as well as the presence of GG genotype could explain a reduction of VDR activity, with subsequent decreased response to vitamin $\mathrm{D}$ and potential immunity deregulation leading to JIA.

\section{Disclosure of interest}

None declared.

\section{Authors' details}

${ }^{1}$ Internal Medicine, Rheumatology Section, Transition Clinic, Italy. ${ }^{2}$ Surgery and Translational Medicine, University of Florence, Florence, Italy. ${ }^{3}$ Institute of Paediatrics, Università Cattolica Sacro Cuore, Rome, Italy. ${ }^{4}$ Endocrinology Unit, Anna Meyer Children's Hospital, Florence, Italy. ${ }^{5}$ Internal Medicine, Rheumatology Section, University of Florence, Florence, Italy.

Published: 5 December 2013

doi:10.1186/1546-0096-11-S2-P66

Cite this article as: Falcini et al.: PReS-FINAL-2053: Vitamin D receptor polymorphisms in a cohort of Italian patients with juvenile idiopathic arthritis. Pediatric Rheumatology 2013 11(Suppl 2):P66. 